\title{
Objectively monitored patching regimens for treatment of amblyopia: randomised trial
}

\author{
Catherine E Stewart, department of health research fellow, ${ }^{1}$ David A Stephens, professor of statistics, ${ }^{2}$ \\ Alistair R Fielder, professor of ophthalmology, ${ }^{1}$ Merrick J Moseley, senior lecturer ${ }^{1}$, for the ROTAS \\ Cooperative
}

1Department of Optometry and Visual Science, City University, London EC1V OHB

${ }^{2}$ Department of Mathematics and Statistics, McGill University, Montreal, QC, Canada H3A 2K6

Correspondence to: M J Moseley m.j.moseley@city.ac.uk

doi:10.1136/bmj.39301.460150.55

\section{ABSTRACT}

Objectives To compare visual outcome in response to two prescribed rates of occlusion (six hours a day and 12

hours a day).

Design Unmasked randomised trial.

Setting Research clinics in two London hospitals.

Participants 97 children with a confirmed diagnosis of

amblyopia associated with strabismus, anisometropia, or both.

Interventions: 18 week period of wearing glasses (refractive adaptation) followed by occlusion prescribed ("patching") for six or 12 hours a day.

Main outcome measures Visual acuity measured by logMAR letter recognition; objectively monitored rate of occlusion (hours a day).

Results The mean age of children at study entry was 5.6 (SD 1.5) years. Ninety were eligible for occlusion but 10 dropped out in this phase, leaving 80 children who were randomised to a prescribed dose rate of six $(n=40)$ or 12 $(n=40)$ hours a day. The mean change in visual acuity of the amblyopic eye was not significantly different $(P=0.64)$ between the two groups $(0.26$ ( $95 \%$ confidence interval 0.21 to 0.31 ) log units in six hour group; 0.24 (0.19 to $0.29) \log$ units in 12 hour group). The mean dose rates (hours a day) actually received, however, were also not significantly different (4.2 (3.7 to 4.7) in six hour group $v$ 6.2 (5.1 to 7.3) in 12 hour group; $P=0.06$ ). The visual outcome was similar for those children who received three to six hours a day or more than six to 12 hours a day, but significantly better than that in children who received less than three hours a day. Children aged under 4 required significantly less occlusion than older children. Visual outcome was not influenced by type of amblyopia. Conclusions Substantial (six hours a day) and maximal (12 hours a day) prescribed occlusion results in similar visual outcome. On average, the occlusion dose received in the maximal group was only $50 \%$ more than in the substantial group and in both groups was much less than that prescribed. Younger children required the least occlusion.

Trials registration Clinical Trials NCT00274664.

\section{INTRODUCTION}

The developing visual system is highly sensitive to visual experience. ${ }^{12}$ Interruption by any obstacle, such as blurred vision or strabismus before about 7 years, results in a reduction of visual capacity known as amblyopia. ${ }^{13}$ About $90 \%$ of work in the children's eye services is related to amblyopia, ${ }^{4}$ and the condition carries an increased lifetime risk (at least three times that of the general population) of serious loss of vision in the other eye..$^{5}$

In animal models, deficits caused by early monocular deprivation can be corrected to normal or near normal levels if treatment is initiated early in life. ${ }^{67}$ Though such studies have increased our understanding of the sensitivity of the developing visual system, they cannot tell us how children with amblyopia will respond.

Treatment of amblyopia has two main components: refractive correction by glasses and occlusion (by "patching") or "penalisation" (by pharmacological or optical means) of the other eye. The improvement attributable to wearing glasses (that most children with amblyopia require) takes considerable time, ${ }^{4-10}$ a process we call "refractive adaptation." ${ }^{910}$ Although wearing glasses and patching may both improve vision, their individual contributions to outcome are not differentiated from each other either in routine clinical practice or research as they are often prescribed together. Understanding of the dose-response of occlusion is further impeded by the failure to monitor how much of the prescribed treatment a child actually receives. The two studies that have used objective monitoring showed that compliance is rarely total and that it differs unpredictably from that prescribed. ${ }^{411}$ Compliance (concordance) with occlusion inflicts a considerable burden on the child and family because of a range of factors including skin irritation, forced use of an eye with degraded vision, poor cosmesis, and lengthy treatment periods.

Though studies have provided good evidence that occlusion therapy can improve the vision of amblyopic eyes, ${ }^{1213}$ results suggest that "maximal" doses (12 hours a day) are no more beneficial than "substantial" doses (six hours a day). Despite these important results, many clinicians in the United States think that this new evidence $^{14}$ is insufficient to initiate a change from traditional treatment methods that are based on "beliefs, from years of experience." ${ }^{\text {"15 }}$ One objection raised is 


\section{Terminology}

Refractive adaptation phase: a time period during which an improvement in vision of the amblyopic eye may occur in response to optical correction alone. Sometimes referred to as "spectacle adaptation" or "optical treatment of amblyopia"

Occlusion phase: a time period in which patching by an opaque patch of the fellow eye (better seeing eye) was randomly prescribed for six or 12 hours a day

Dose rate: mean number of hours patched a day within the occlusion phase

Total (accumulated) dose: total number of hours patched within the occlusion phase Time in occlusion: number of days spent in the occlusion phase

Residual amblyopia: difference in visual acuity between amblyopic and fellow eye at completion of treatment

Proportion of amblyopic deficit corrected: VAas-VAae/VAas-VAfe, where VAas=visual acuity of amblyopic eye at baseline; VAae=best visual acuity of the amblyopic eye by trial end; and VAfe=best visual acuity of fellow eye by trial end

Optimum dose: The minimum dose a child requires to achieve their best visual acuity

that patching in these trials was not objectively monitored. ${ }^{16}$ The researchers acknowledged that they could not state with confidence that the children in the randomised groups actually received significantly different amounts of occlusion. ${ }^{12} 13$

Accurate knowledge of the amount of occlusion a child actually receives is a prerequisite for determining a dose-response relation and is fundamental to evidence based prescribing. Our group ${ }^{17}$ and another ${ }^{18}$ have developed an objective measuring device - the occlusion dose monitor - to determine the amount of patching worn. Using this monitor we have previously shown a positive, almost linear, dose-response up to 400 hours ${ }^{419}$ with most improvement occurring in the first six weeks of patching. ${ }^{4}$

We compared two commonly used occlusion regimens - substantial (six hours a day) and maximal (12 hours a day). In this randomised trial of occlusion regimens we fully differentiated the effects of refractive adaptation from those of patching, objectively monitored occlusion, and used recently described methods of quantifying outcome. ${ }^{20}$

\section{METHODS}

Study participants

Children were recruited from two London hospitals from February 2002 to May 2004. Included children were aged 3-8 years and had anisometropia or strabismus, or both; a significant difference in interocular acuity (at least $0.1 \log \mathrm{MAR}$ - for example, right $6 / 6$, left $<6 / 7.5$ in Snellen notation); no occlusion therapy; and no ocular pathology or learning difficulties. All parents gave consent.

Before study entry, all children had a full ophthalmic assessment including cycloplegic retinoscopy and ophthalmoscopy. The study comprised three phases: baseline, refractive adaptation, and occlusion. In the baseline phase, one author (CES) enrolled participants and the same examiner assessed stability of their visual acuity on at least two occasions. If measures differed by more than $0.1 \log$ units, further assessments were undertaken until measures fell within this criterion.
Children who required correction with glasses (measureable refractive error, defined previously ${ }^{9}$ ) or who had already been wearing glasses for less than 18 weeks entered the refractive adaptation phase. They were instructed to wear glasses all the time and scheduled to return for assessment of vision every six weeks from week 0 (onset of wearing glasses) until 18 weeks of refractive adaptation had been completed: a period that we have previously established would allow for all measurable improvement attributable to wearing glasses to have occurred. ${ }^{9}$ On completion of refractive adaptation, children who still met the study's operational definition of amblyopia (see below) entered the occlusion phase. Those children who did not require correction with glasses or who had previously worn glasses for 18 weeks or longer entered directly into the occlusion phase. CES allocated children to prescribed dose rates of either 12 hours a day (maximal) or six hours a day (substantial) using a random number generator in the statistical package "R" (www.r-project. org/), stratified, but not blocked, by type of amblyopia and implemented by means of a concealed typed allocation list. Neither investigator nor the parents were masked to group allocation.

The occlusion dose monitor ${ }^{21}$ recorded episodes of occlusion to the nearest minute. The monitor consists of an eye patch with two electrodes attached to its undersurface connected by a plastic encapsulated wire lead to a data logger powered by battery. ${ }^{22}$ Visual function was recorded every two weeks, at which time we also audited the occlusion dose received between visits. The occlusion phase continued until visual acuity ceased to improve - as evidenced by either two inflexions of change in acuity (for example, improve/ decline/improve/decline) or three consecutive measurements of acuity not differing by plus or minus $0.02 \mathrm{log}$ units. $^{22}$ On completion of the occlusion phase, children returned to standard clinical care.

\section{Outcome measures}

Our primary outcome measure was logMAR visual acuity. ${ }^{22}$ To encompass the reading ability and age span of the children, we used three logMAR visual acuity charts: ETDRS (Precision Vision, IL, USA), crowded, and uncrowded (Keeler, Windsor). We used standard protocols for visual acuity testing, scored by letter. The type of chart used for each child did not change during the course of the study.

We expressed visual outcome in three ways: firstly, by calculating the change in visual acuity of the amblyopic eye; secondly, by calculating the amount of residual amblyopia (acuity difference between the amblyopic and fellow eye at outcome); and, thirdly, by calculating the proportion of the visual deficit corrected (proportional improvement). ${ }^{20}$ The box gives details of relevant terminology.

\section{Statistical analysis}

We used Wilcoxon signed rank analysis to test for significant differences in outcome and dose between the groups and Kruskal-Wallis one way analysis of 
variance on ranks to test for significant differences in outcome for participants by objectively monitored dose rate. The statistical power of the analyses (based on the outcome of a previously reported study ${ }^{4}$ ) ranged from 0.6 to 0.9 to detect a 0.20 difference in $\log$ MAR values between groups (for ranges of $n=17-41$ ), with $\alpha=0.01$.

\section{RESULTS}

Ninety seven children with a mean age of 5.6 (SD 1.5) years entered the study. Forty two had amblyopia associated with anisometropia (mean age 6.3 (SD 1.4) years), 21 had strabismus (4.7 (SD 1.3) years), and 34 had mixed anisometropia and strabismus (5.3 (SD 1.5) years). Ninety three children had measurable refractive error, although nine had undergone full refractive adaptation before study entry and progressed directly from baseline to the occlusion phase, leaving $84(89 \%)$ children who underwent refractive adaptation (fig 1). No adverse events occurred.

\section{Refractive adaptation phase}

The primary purpose of this phase was to ensure that full refractive adaptation was complete before

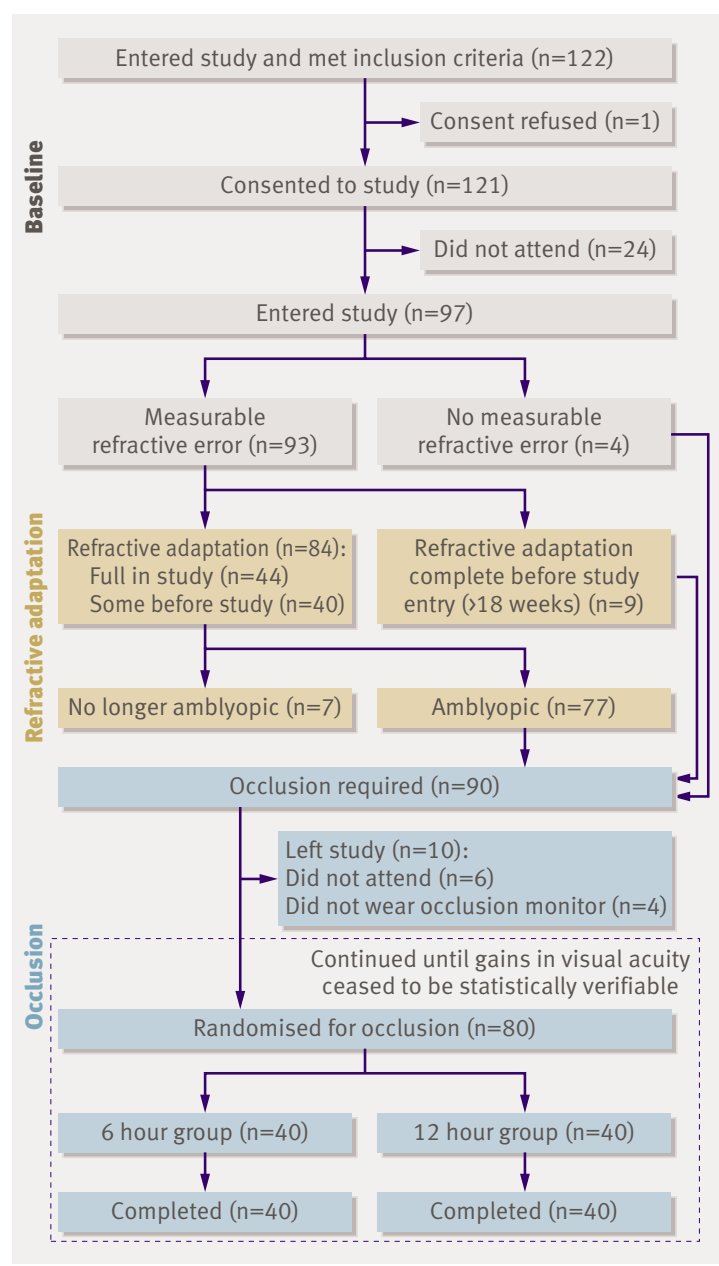

Fig $1 \mid$ Recruitment and retention of participants during three study phases
Table 1 Baseline characteristics of children according to two prescribed occlusion

\begin{tabular}{lcc} 
& \multicolumn{2}{c}{$\begin{array}{c}\text { Prescribed occlusion } \\
\text { (hours/day) }\end{array}$} \\
\cline { 2 - 3 } Mean (SD) baseline visual acuity & $0.45(0.30)$ & $0.44(0.30)$ \\
\hline Type of amblyopia: & & $12(\mathrm{n}=40)$ \\
\hline Anisometropia & 14 & 20 \\
\hline Strabismus & 12 & 7 \\
\hline Mixed & 14 & 13 \\
\hline Mean (SD) age (years) & $5.4(1.7)$ & $5.6(1.4)$ \\
\hline
\end{tabular}

occlusion commenced. The mean (SD) visual acuity of amblyopic eyes improved from 0.55 (0.28) to 0.38 (0.34) logMAR; a mean improvement of 0.17 (95\% confidence interval 0.12 to 0.22 ). In 40 children who had undergone partial refractive adaptation before study entry (with a mean (SD) number of weeks wearing glasses $14(3))$, the mean change in acuity was 0.11 (0.05 to 0.17$)$. The change in acuity in the 44 children who underwent full refractive adaptation monitored in our study was significantly greater $(\mathrm{P}=0.03)$ (mean 0.22 (0.16 to 0.28 ) logMAR units).

During refractive adaptation, visual acuity in seven children improved to an extent that they were no longer eligible to enter the occlusion phase, with mean $\log$ MAR visual acuity $0.00(-0.07$ to 0.07$)$ in the amblyopic eye and $-0.04(-0.10$ to 0.02$)$ in the fellow eye.

\section{Occlusion phase}

Though 90 children were eligible for occlusion, 10 left the study. The 80 remaining were randomised to a prescribed occlusion dose rate of $\operatorname{six}(n=40$; age 5.4 , SD $1.7)$ or 12 hours a day $(n=40$; age 5.6 , SD 1.4) (table 1). In the six hour group, the mean (SD) visual acuity in the amblyopic eye improved from $0.45(0.30)$ to $0.19(0.19) \operatorname{logMAR}$, a change of 0.26 (95\% confidence interval 0.21 to 0.31$) \log$ units. In the 12 hour group, the mean (SD) improvement was from 0.44 $(0.30)$ to $0.20(0.24)$ logMAR, a change of 0.24 (0.19 to 0.29 ) $\log$ units (table 2). There was no significant difference between the two groups for any outcome measure (visual acuity at start and end, magnitude of change in acuity, amount of residual amblyopia, or proportion of the amblyopia deficit corrected) (table 2).

The mean dose rates (hours a day) actually received were not significantly different (4.2 (3.7 to 4.7) in the six hour group $v 6.2$ (5.1 to 7.3) in the 12 hour group; $\mathrm{P}=0.06$ ) (fig 2). Correspondingly, there was no difference in the total (accumulated) dose received by children in either of the two groups $(\mathrm{P}=0.03)$ (fig 3). Only nine $(23 \%)$ and three $(7 \%)$ children in the two groups, respectively, achieved an average concordance within $10 \%$ of their prescribed dose rate. Concordance was 3.6 times more variable in the 12 hour group than in the six hour group. 
Table 2 | Mean (95\% confidence interval) visual outcome according to prescribed dose of occlusion (six or 12 hours a day) and actual dose received*

\begin{tabular}{|c|c|c|c|c|c|c|}
\hline & $\begin{array}{l}\text { Change in visual } \\
\text { acuity }\end{array}$ & $\begin{array}{l}\text { Proportion of deficit } \\
\text { corrected }\end{array}$ & Residual amblyopia & $\begin{array}{l}\text { Cumulative dose } \\
\text { (hours) }\end{array}$ & $\begin{array}{l}\text { Dose rate (hours/ } \\
\text { day) }\end{array}$ & $\begin{array}{c}\text { Time to best visual } \\
\text { acuity (days) }\end{array}$ \\
\hline \multicolumn{7}{|c|}{ Prescribed occlusion dose (hours/day) } \\
\hline $6(n=39)$ & $0.26(0.21$ to 0.31$)$ & 0.67 (0.57 to 0.77$)$ & $0.17(0.11$ to 0.23$)$ & 225 (183 to 267$)$ & $4.2(3.7$ to 4.7$)$ & 59 (49 to 69) \\
\hline $12(n=41)$ & 0.24 (0.18 to 0.30$)$ & 0.61 (0.50 to 0.72$)$ & 0.22 (0.15 to 0.29$)$ & 307 (240 to 384) & $6.2(5.1$ to 7.3$)$ & 54 (44 to 64) \\
\hline Difference & $0.02(0.0$ to 0.04$)$ & 0.06 (0.03 to 0.09$)$ & $0.05(0.03$ to 0.07$)$ & $82(63$ to 101$)$ & $2.0(1.7$ to 2.3$)$ & 05 (1.8 to 8.8) \\
\hline$P$ value & 0.64 & 0.34 & 0.25 & 0.30 & 0.06 & 0.48 \\
\hline \multicolumn{7}{|c|}{ Received occlusion dose (hours/day) } \\
\hline$\leq 3(n=21)$ & $0.18(0.11$ to 0.25$)$ & $0.33(0.16$ to 0.50$)$ & $0.31(0.25$ to 0.37$)$ & 87 (51 to 123$)$ & $1.6(1.3$ to 1.9$)$ & $70(51$ to 89$)$ \\
\hline$>3-6(n=32)$ & $0.25(0.18$ to 0.32$)$ & 0.77 (0.67 to 0.87$)$ & $0.10(0.06$ to 0.14$)$ & 255 (213 to 297 ) & $4.3(4.0$ to 4.6$)$ & $66(55$ to 77$)$ \\
\hline Difference & 0.07 (0.06 to 0.12$)$ & 0.44 (0.39 to 0.49$)$ & 0.21 (0.19 to 0.23$)$ & 168 (153 to 181$)$ & $2.7(2.6$ to 2.8$)$ & $4(-2$ to 10$)$ \\
\hline$P$ value & 0.04 & 0.004 & $<0.001$ & $<0.001$ & $<0.001$ & 0.68 \\
\hline$\leq 3(n=21)$ & $0.18(0.11$ to 0.25$)$ & $0.33(0.16$ to 0.50$)$ & $0.31(0.25$ to 0.37$)$ & 87 (51 to 123$)$ & $1.6(1.3$ to 1.9$)$ & 70 (51 to 89$)$ \\
\hline$>6-12(n=27)$ & $0.33(0.25$ to 0.41$)$ & 0.67 (0.55 to 0.79$)$ & $0.16(0.10$ to 0.22$)$ & 403 (310 to 500$)$ & 9.0 (7.8 to 10.2$)$ & $50(40$ to 60$)$ \\
\hline Difference & 0.15 (0.12 to 0.18$)$ & 0.34 (0.28 to 0.40$)$ & 0.15 (0.12 to 0.18$)$ & 316 (279 to 353$)$ & 7.4 (7.1 to 7.7$)$ & 20 (12 to 28$)$ \\
\hline$P$ value & 0.01 & 0.01 & 0.004 & $<0.001$ & $<0.001$ & 0.04 \\
\hline $33-6(n=32)$ & 0.25 (0.18 to 0.32$)$ & 0.77 (0.67 to 0.87$)$ & $0.10(0.06$ to 0.14$)$ & 255 (213 to 297$)$ & $4.3(4.0$ to 4.6$)$ & 66 (55 to 77$)$ \\
\hline$>6-12(n=27)$ & $0.33(0.25$ to 0.41$)$ & 0.67 (0.55 to 0.79$)$ & $0.16(0.10$ to 0.22$)$ & 403 (310 to 500) & 9.0 (7.8 to 10.2$)$ & 50 (40 to 60$)$ \\
\hline Difference & $0.08(0.05$ to 0.11$)$ & $0.10(0.06$ to 0.14$)$ & $0.06(0.04$ to 0.08$)$ & 148 (122 to 174$)$ & 4.7 (4.4 to 5.0$)$ & $16(12$ to 20$)$ \\
\hline$P$ value & 0.13 & 0.08 & 0.11 & $<0.001$ & $<0.001$ & 0.18 \\
\hline
\end{tabular}

* One child received dose rate of only 0.2 hours (12.5 minutes a day), an amount with doubtful therapeutic value. Significance values are unchanged with or without this data point.

The mean dose rate and the mean percentage concordance with the prescribed regimen did not differ significantly with age (table 3 ). Also, the mean dose rate of occlusion did not differ significantly with type of amblyopia, even when we stratified by prescribed dose rate $(\mathrm{P}=0.05)$.

We also analysed the data by objectively monitored dose rate (that is, received rather than prescribed). Children were categorised into three groups according to the dose rate received in hours a day: $<3(n=22), \geq 3-6$ $(\mathrm{n}=32)$, and $\geq 6-12(\mathrm{n}=27)$. We found a significant difference in visual outcome between children who received less than three hours a day compared with those in the other two groups, with no difference between the latter (table 2). There was a significant

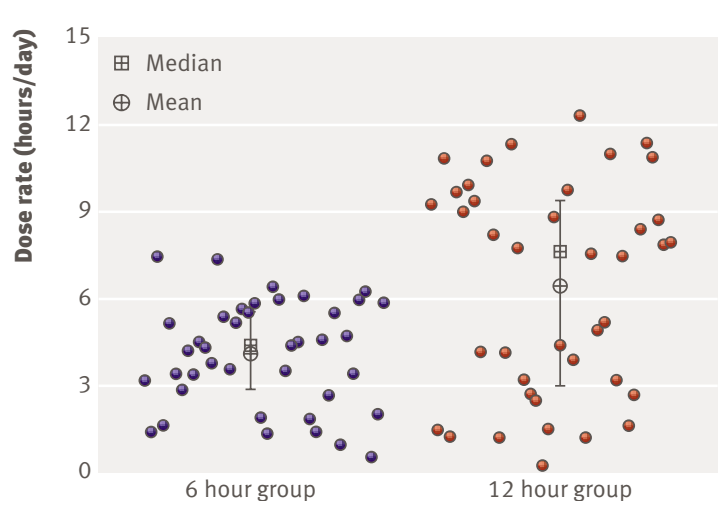

Fig 2 Achieved dose rate in children allocated to six or 12 hours of occlusion a day. Vertical lines indicate interquartile range. To enhance clarity, dots have been jittered horizontally trend for improved visual outcome (greater change in visual acuity and proportional improvement, less residual amblyopia) with increasing dose rates up to four hours a day (figs 4).

\section{Duration of occlusion therapy}

The mean time to achieve best visual acuity was nine weeks (SD 5, range 2-26 weeks). Only 12 children (eight in the six hour group; four in the 12 hour group) required more than 14 weeks of occlusion. The mean time to achieve best visual acuity did not differ significantly between the prescribed groups ( 10 weeks (SD 6, range 2-26) in the six hour group $v$ eight weeks (SD 5, range 1-18) in the 12 hour group). Most of the improvement occurred in the first six

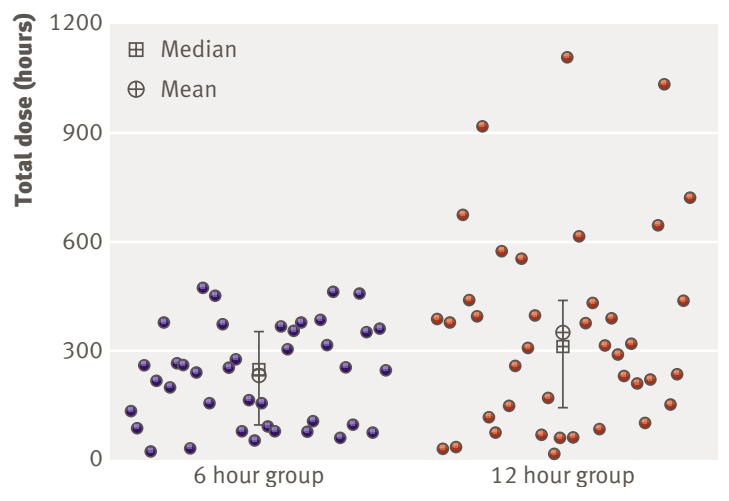

Fig 3 Total dose of occlusion actually received in children allocated to six or 12 hours of occlusion a day. Vertical lines indicate interquartile range. To enhance clarity, dots have been jittered horizontally 


\begin{tabular}{|c|c|c|}
\hline & Mean $(95 \% \mathrm{Cl})$ & Pvalue \\
\hline \multicolumn{3}{|c|}{ Dose rate (hours/day): } \\
\hline$\ll 4$ years & $4.05(2.65$ to 5.45$)$ & \multirow[t]{3}{*}{0.48} \\
\hline 4-6 years & 4.65 (3.45 to 5.85$)$ & \\
\hline$>6$ years & 5.55 (4.45 to 6.45$)$ & \\
\hline \multicolumn{3}{|c|}{ Percentage concordance in 6 hour group: } \\
\hline$\ll 4$ years & $53(27$ to 79$)$ & \multirow[t]{3}{*}{0.45} \\
\hline $4-6$ years & 72 (55 to 89$)$ & \\
\hline 16 years & $69(57$ to 81$)$ & \\
\hline \multicolumn{3}{|c|}{ Percentage concordance in 12 hour group: } \\
\hline$\ll 4$ years & 41 (24 to 58$)$ & \multirow[t]{3}{*}{0.69} \\
\hline 4-6 years & $47(30$ to 64$)$ & \\
\hline$>6$ years & 58 (46 to 70$)$ & \\
\hline \multicolumn{3}{|c|}{ Dose rate (hours/day): } \\
\hline Anisometropia & 5.19 (4.19 to 6.19$)$ & \multirow[t]{3}{*}{0.48} \\
\hline Strabismus & 5.79 (4.39 to 7.19$)$ & \\
\hline Mixed & $4.56(3.46$ to 5.66$)$ & \\
\hline
\end{tabular}

weeks ( $53 \%$ by two weeks, $68 \%$ by four weeks, $78 \%$ by six weeks, $85 \%$ by eight weeks).

Factors affecting outcome as a function of dose rate The proportion of the deficit corrected and residual amblyopia were not significantly different $(\mathrm{P}=0.46$ and $\mathrm{P}=0.42$, respectively) for each type of amblyopia. The mean (95\% confidence interval) proportions of deficit corrected were 0.60 (0.48 to 0.72 ) for anisometropia, 0.67 ( 0.54 to 0.80$)$ for mixed, and 0.67 (0.52 to $0.82)$ for strabismus. The mean residual amblyopia was 0.18 ( 0.13 to 0.23$) ; 0.23$ (0.13 to 0.33$)$, and 0.20 (0.07 to $0.32)$, respectively.

There was a significant difference in the dose rate required to obtain maximum proportional improvement with respect to age (table 4 , fig 5). For those children under 4 years of age, we observed significant gains in the proportion of the deficit corrected even at low dose rates (0-3 hours a day) with marginal but not significant $(\mathrm{P}=0.54)$ additional gains for doses over three hours a day (table 4$)$. In contrast, children aged 4-6 and over 6 years showed significant differences $(\mathrm{P}=0.03$ and $\mathrm{P}<0.001$, respectively) between none to three hours a day and up to six hours a day but no difference between three to six and six to 12 hours a day. Children aged over 6 who wore a patch up to three hours a day had little deficit corrected. To gain equivalent proportional improvement in children aged under

Table 4 | Proportion of deficit corrected (means and $95 \%$ confidence intervals) grouped by age at start of occlusion and dose rate received

\begin{tabular}{lcccc} 
Age (years) & $\leq 3$ hours/day $(n=22)$ & >3-6 hours/day $(n=32)$ & >6-12 hours/day $(n=27)$ & P value \\
$<4(n=20)$ & $0.53(0.34$ to 0.72$)$ & $0.66(0.46$ to 0.86$)$ & $0.68^{*}$ & 0.54 \\
\hline $4-6(n=32)$ & $0.49(0.30$ to 0.68$)$ & $0.80(0.67$ to 0.93$)$ & $0.60(0.38$ to 0.82$)$ & 0.03 \\
\hline$>6(n=17)$ & $0.17(-0.1$ to 0.44$)$ & $0.83(0.61$ to 1.05$)$ & $0.67(0.45$ to 0.89$)$ & $<0.001$ \\
\hline P value & 0.03 & 0.23 & 0.97 & -
\end{tabular}

*Denotes single data point. P values refer to comparison between 33 hours/day and the two other groups (3-6 hours/day and $>6-12$ hours/day) and between age $\leq 6$ and $>6$ years.

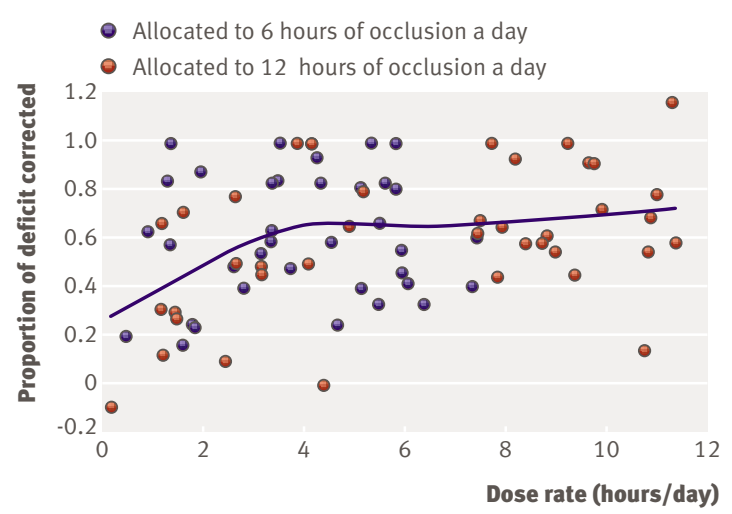

Fig 4 | Dose rate and proportion of deficit corrected according to prescribed regimen. Fitted lines are default LOWESS (locally weighted smoothed) line of best fit

6 , those aged over 6 needed to achieve a dose rate over three hours a day.

\section{DISCUSSION}

Substantial (six hours a day) and maximal (12 hours a day) prescribed occlusion regimens provide equivalent visual outcome for the treatment of unilateral amblyopia in children aged 3-8. These findings agree with those from a previous study. ${ }^{13}$ By objectively monitoring occlusion we showed that the maximal group received only about 50\% more occlusion a day, despite being prescribed twice the rate in the substantial group. Furthermore, analysis of dose-response showed that the average amount of occlusion received in each group was sufficient to achieve best outcome. Researchers have previously raised the possibility that similar outcomes seen with different prescribed occlusion rates could be because similar rates were actually received, but the study did not include any objective monitoring. ${ }^{13}$

\section{Optimum dose rate}

We carried out exploratory analyses on the effect of received dose rate and on dose rate and age. The relation between dose rates and outcome showed that

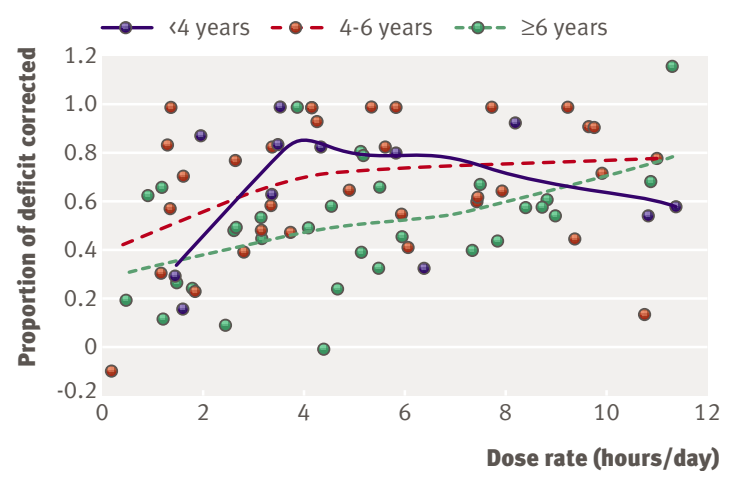

$\overline{\text { Fig } 5}$ | Age of children at start of occlusion as a function of age. Fitted lines are default LOWESS (locally weighted smoothed) line of best fit 
outcome was similar in children receiving between four and 12 hours a day. We observed a linear relation between improved outcome and increased dose rate for dose rates up to four hours a day (fig 4), and our analysis suggests that achieving an initial dose rate of three to four hours a day should be a clinical priority. The response depends on age, however, so that for those under 4 years this could be reduced. Higher dose rates achieve the best outcome more rapidly but at a risk of accumulating excessive non-therapeutic hours of patching. Thus, patching for all waking hours is almost certainly excessive.

We consider that the observed effect of dose prescribed (that is, in the intention to treat analysis) was not compromised by potential confounding of other variables (for example, type of amblyopia, age of child, visual acuity at start of study). The imperfect adherence to assigned treatment, however, implies that an observational analysis that inspects the effect of dose received may be subject to confounding. A carefully constructed multiple regression analysis of causal inference methods would therefore be required to analyse the data on dose received. ${ }^{19}$

\section{Concordance}

Eye patching can cause considerable distress for both the child and family. ${ }^{2324}$ Full concordance with prescribed dose rates is rare; children in our study received on average $66 \%$ and $50 \%$ of their prescribed occlusion of six and 12 hours a day, respectively. This suggests that these prescribed regimens imposed a considerable burden on our participants and would be expected to do so in routinely treated patients. We observed a plateau of improvement in outcome at about four hours a day. Prescriptions of occlusion should take this into account, minimising the amounts necessary for best expected outcome.

The conventional clinical approach in a child whose vision does not improve with part time occlusion therapy is to prescribe a more intense regimen, ${ }^{16}$ thus increasing the burden of treatment on the child and family. ${ }^{492324}$ Knowledge of concordance with treatment permits detailed evaluation of treatment strategy. For example, if compliance was low initially then this could be the reason for poor outcome, in which case education ${ }^{25}$ or different patching strategies may facilitate best outcome. If concordance was high, however, additional occlusion will probably not be beneficial.

\section{Objective monitoring of occlusion}

Our study highlights the benefits of objective monitoring of occlusion within routine clinical practice. Firstly, clinicians no longer have to rely on subjective and qualitative feedback from children and parents as to the amount of patching achieved. Secondly, the availability of an objective quantitative record of the occlusion dose and dose rate allows the clinician to tailor advice and prescription to an individual patient. In practical terms, this will reduce the number of patching hours prescribed and clinic visits required. This should result in an improvement in cost effectiveness and potentially a better experience for the child and his or her family.

Although treatment for amblyopia is thought to be more successful at earlier stages of visual development, ${ }^{26}$ the evidence is unconvincing and contradictory. ${ }^{26-32} \mathrm{We}$ have provided further evidence that age can influence effectiveness. It seems that patching dose rate is the predictive factor of whether older children (over 6 years) can be treated successfully. Thus the child under 4 years responds both more rapidly and with less occlusion than the older child, but the final level of attainment for all ages between 3 and 8 years is the same. The data provide further evidence of the timing and plasticity within the sensitive period for visual recovery. Towards the end of the visual sensitive period, however, it seems that the deficit becomes more resistant and less plastic, requiring more occlusion to achieve the same outcome.

We did not intend to provide specific evidence based guidelines for the treatment of amblyopia as this would require further accumulation of evidence (such as on the influence of the severity of amblyopia). Our results, however, suggest that a typical amblyopic child (in this study a child with a mean acuity of $0.45 \log$ MAR after refractive adaptation who improved by $0.26 \log$ MAR as a result of occlusion) would require an accumulation in the region of 180-270 received hours of patching at an average dose rate of four hours a day (table 2 and figure 4).

Dose-response analysis of amblyopia therapy is a novel approach that can elucidate the kinetics of the sensitive period in humans. By fine tuning therapeutic strategies it will be possible to facilitate evidence based treatment plans specific for each child. This will reduce the burden of amblyopia treatment for the child and family and, ultimately, for health service providers.

We thank all the children and parents who took part in the study and the members of the ROTAS Cooperative (Tricia Rice, Rowena McNamara, Avril Charnock, Clare Baldwin, Naheem Abbas)

Contributors: All authors contributed to the design. CES was responsible fo the day to day management of the study. ARF and CES were responsible for the clinical examination of participants. CES and DAS analysed the data. CES drafted the manuscript, which was revised by all authors. ARF is guarantor Funding: ROTAS was funded by a project grant from Fight for Sight, UK. None of the authors were employees, trustees, or advisers to Fight for Sight during the period the funding application was under consideration. Competing interests: None declared.

Ethical approval: Hillingdon and St Mary's Hospitals London NHS Trusts' local research ethics committees.

Provenance and peer review: Non-commissioned; externally peer reviewed.

1 Hubel DH, Wiesel TN. The period of susceptibility to the physiological effects of unilateral eye closure in kittens. J Physiol 1970;206:419-36

2 Daw NW. Critical periods in the visual system. In: Hopkins B, Johnson SP, eds. Neurobiology of infant vision. Westport, CT: Praeger, 2003:43-103.

3 Blakemore C, Garey L, Vital-Durand F. The physiological effects of monocular deprivation and their reversal in the monkey's cortex. Physiol 1978;283:223-62.

4 Stewart CE, Moseley MJ, Stephens DA, Fielder AR, the MOTAS cooperative. The treatment dose-response in amblyopia therapy: results from the monitored occlusion treatment of amblyopia study (MOTAS) Invest Ophthalmol Vis Sci 2004:45:3048-54.

5 Rahi J, Logan S, Timms C, Russell-Eggitt I, Taylor D. Risk, causes and outcomes of visual impairment after loss of vision in the non- 


\section{WHAT IS ALREADY KNOWN ON THIS TOPIC}

Occlusion therapy (patching) is the main treatment for amblyopia

It is an unpleasant procedure and compliance with treatment is often poor

Given the inability to record objectively the amount of occlusion a child actually receives, many practitioners prescribe large doses, above six hours a day

\section{WHAT THIS STUDY ADDS}

Results of occlusion do not differ in groups prescribed six or 12 hours of occlusion a day

Objective monitoring shows that the amount of occlusion a child actually receives is

substantially less than that prescribed, irrespective of dosing regimen

amblyopic eye: a population-based study. Lancet 2002;360:597-602.

6 Harweth RS, Smith EL, Crawford MLI, von Noorden GK. The effects of reverse monocular deprivation in monkeys. I. Psychophysical experiments. Exp Brain Res 1989;74:327-37.

7 LeVay S, Wiesel TN, Hubel DH. The development of ocular dominance columns in normal and visually deprived monkeys. / Comp Neurol 1980;191:1-51.

8 Pediatric Eye Disease Investigator Group. Treatment of anisometropic amblyopia in children with refractive correction. Ophthalmology 2006;113:895-903.

9 Moseley MJ, Neufield M, McCarry B, Charnock A, McNamara R, Rice T. Remediation of refractive amblyopia by optical correction alone. Ophthalmic Physiol Opt 2002;22:296-9.

10 Stewart CE, Moseley MJ, Stephens DA, Fielder AR, on behalf of the MOTAS cooperative. Refractive adaptation in amblyopia: quantification of effect and implications for practice. Br J Ophthalmol 2004;88:1552-6.

11 Awan M, Proudlock FA, Gottlob I. A randomized controlled trial of unilateral strabismic and mixed amblyopia using occlusion dose monitors to record compliance. Invest Ophthalmol Vis Sci 2005;46:1435-9.

12 Pediatric Eye Disease Investigator Group. A randomized trial of patching regimens for treatment of moderate amblyopia in children. Arch Ophthalmol 2003;121:603-11.

13 Pediatric Eye Disease Investigator Group. A randomized trial of prescribed patching regimens for treatment of severe amblyopia in children. Ophthalmology 2003;110:2075-87.

14 Von Noorden GK, Campos EC. Patching regimens. Ophthalmology 2004;111:1063.

15 Wygnanski-Jaffe T. The effect on pediatric ophthalmologists of the randomized trial of patching regimens for treatment of moderate amblyopia. J AAPOS 2005;9:208-11.
16 Kushner BJ. Patching regimens for amblyopia. Ophthalmology 2004; $112: 736$

17 Fielder AR, Auld R, Irwin M, Cocker KD, Jones HS, Moseley MJ. Compliance monitoring in amblyopia therapy. Lancet 1994;343:547.

18 Loudon SE, Polling JR, Simonsz HJ. A preliminary report about the relation between visual acuity increase and compliance in patching therapy for amblyopia. Strabismus 2002;10:79-82.

19 Stewart CE, Stephens DA, Fielder AR, Moseley MJ, MOT AS Cooperative. Modelling dose-response in amblyopia: toward a child-specific treatment plan. Invest Ophthalmol Vis Sci 2007;48:2589-94.

20 Stewart CE, Moseley MJ, Fielder AR. Defining and measuring treatment outcome for unilateral amblyopia Br J Ophthalmol 2003;87:1229-31.

21 Fielder AR, Irwin M, Auld R, Cocker KD, Jones HS, Moseley MJ. Compliance monitoring in amblyopia therapy: objective monitoring of occlusion. Br J Ophthalmol 1995;79:585-9.

22 Stewart CE, Fielder AR, Stephens DA, Moseley MJ. Design of the monitored occlusion treatment of amblyopia study (MOTAS). $\mathrm{Br}$ Ophthalmol 2002;86:915-9.

23 Hrisos S, Clarke MP, Wright CM. The emotional impact of amblyopia treatment in preschool children. Ophthalmology 2004;111:1550-6.

24 Searle A, Norman P, Harrad R, Vedhara K. Psychosocial and clinical determinants of compliance with occlusion therapy for amblyopic children. Eye 2002;16:150-5.

25 Newsham D. A randomised controlled trial of written information: the effect on parental non-compliance with occlusion therapy. $\mathrm{Br}$ J Ophthalmol 1997;86:787-91.

26 Massie $\mathrm{H}$. Fixing eye for occlusion: survey of 1,000 cases of patients receiving occlusion of the fixing eye. Trans Ophthalmol Soc Aust 1965;24:39-46.

27 Hiscox FN, Strong N, Thompson JR, Minshull C, Woodruff G. Occlusion for amblyopia: a comprehensive survey of outcome. Eye 1992;6:300-4.

28 Lea HSJ, Rubenstein JLMP. The sensitive period for anisometropic amblyopia. Eye 1989;3:783-90.

29 Kutschke PJ, Scott WE, Keech RV. Anisometropic amblyopia. Ophthalmology 1991;98:259-63.

30 Cobb CJ, Russell K, Cox A, MacEwan CJ. Factors influencing visual outcome in anisometropic amblyopes. BrJ Ophthalmol 2002;86:1278-81.

31 Flynn JT, Woodruff G, Thompson JR, Hiscox F, Fever W, Shiftman J. The therapy of amblyopia: an analysis comparing the results of amblyopia therapy utilizing two pooled sets. Trans Am Ophthalmol Soc 1999;97:373-90.

32 Fulton AB, Mayer DL. Esotropic children with amblyopia: effects of patching on acuity. Graefes Arch Clin Exp Ophthalmo 1988;226:309-12.

Accepted: 16 July 2007 